http://www.jfas.info

\title{
INFLUENCES OF SACCHARIDES TYPES AND INITIAL GLUCOSE CONCENTRATION ON MICROBIAL CELLULOSE PRODUCTION BY G. XYLINUS
}

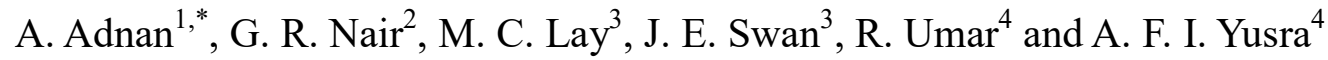

${ }^{1}$ School of Fundamental Science, Universiti Malaysia Terengganu, 21030 Kuala Terengganu, Terengganu, Malaysia

${ }^{2}$ Department of Biotechnology and Biochemical Engineering, Sree Buddha College of Engineering, Pattoor, P.O., Allapuzha-690529, India

${ }^{3}$ School of Engineering, Faculty of Science and Engineering, University of Waikato, Private Bag 3105, Hamilton, New Zealand

${ }^{4}$ East Coast Environmental Research Institute (ESERI), Universiti Sultan Zainal Abidin, Gong Badak Campus, 21300 Kuala Terengganu, Terengganu, Malaysia
\end{abstract}

Published online: 08 August 2017

\begin{abstract}
Microbial cellulose $\left(\mathrm{C}_{6} \mathrm{H}_{10} \mathrm{O}_{5}\right)_{n}$ is a remarkable polysaccharide and has excellent characteristics as a highly potential biomaterial. To enhance microbial cellulose concentration in aerated and agitated cultivation, the influences of three different saccharides and initial glucose concentrations were investigated. Tests on agar slants and in agitated shake flasks using glucose, sucrose and lactose media exhibited that the cellulose producer, Gluconacetobacterxylinus DSM 46604 resembled good growth on glucose and produced cellulose. However, there was negligible growth on sucrose and lactose media.
\end{abstract}

Author Correspondence, e-mail: azila.adnan@umt.edu.my

doi: http://dx.doi.org/10.4314/jfas.v9i2s.13 
Further experiments with initial glucose concentrations between 40 and $100 \mathrm{~g} / \mathrm{L}$ were carried out for five days. The maximum microbial cellulose concentration of $1.13 \mathrm{~g} / \mathrm{L}$ was obtained from $50 \mathrm{~g} / \mathrm{L}$ glucose media.

Keywords: microbial cellulose; glucose concentrations; shake flasks; Gluconacetobacterxylinus.

\section{INTRODUCTION}

According to [1], cellulose is the most bountiful organic polymer that is mostly produced by vascular plants. Production of cellulose from microbial system can reduce the demand of plant-based cellulose [2]. Microbial cellulose, which is produced by an aerobe bacterium, is obtained from aerobic fermentation. It possessed excellent features, for example, high degree of crystallinity and high degree of polymerization [3]. Compared to plant-based cellulose, microbial cellulose has high crystallinity, high mechanical strength and higher purity. The latter does not contain lignin and hemicellulose that present in plant-based cellulose [4-5]. Due to those properties, microbial cellulose is suitable biomaterial to be applied in paper industry, high precision acoustic speakers manufacturing, high quality paper and food industry [6-7]. Different saccharides for example oligosaccharides, monosaccharides, alcohols and organic acids have been utilized to improve the microbial cellulose production [8-9]. Microbial cellulose is secreted by various genera of bacteria for example, Gluconacetobacter (formerly known asAcetobacter), Agrobacterium, Aerobacter, Achromobacter, Azotobacter, Rhizobium, Sarcina and Salmonella [10]. Microbial cellulose which produced from a non-pathogenic Gluconacetobacterxylinus was first outlined by [11]. Most acetic acid bacteria can produce microbial cellulose, however Gluconacetobacterxylinus is reported to be the most efficient producer [10-12]. The main issue in microbial cellulose production is its production is relatively low, thus several attempts have been conducted to improve its yield. In this study, the influence of saccharides and initial saccharide concentration on microbial cellulose concentration inshake flasks cultivation were investigated.

\section{METHODOLOGY}

\subsection{Influence of Saccharide Types on G. xylinus Growth}


The bacterium was grown at $30^{\circ} \mathrm{C}$ on three different agar slants and three different shake flasks containing: Fifty g/L D-glucose/sucrose/lactose, $5 \mathrm{~g} / \mathrm{L}$ yeast extract, $5 \mathrm{~g} / \mathrm{L}$ ammonium sulphate, $3 \mathrm{~g} / \mathrm{L}$ disodium hydrogen phosphate, $0.05 \mathrm{~g} / \mathrm{L}$ magnesium heptahydrate and $20 \mathrm{~g} / \mathrm{L}$ agar. All agar slants and shake flasks were incubated for 5 days. The carbon source that produced lavish amount of growth on agar slants was used in further investigation.

\subsection{Influence of Initial Glucose Concentration on Microbial Cellulose Production}

To study the influence of initial glucose concentration, 40, 50, 60, 80 or $100 \mathrm{~g}$ per liter glucose was supplemented to the media, which contained $5 \mathrm{~g} / \mathrm{L}$ yeast extract, $5 \mathrm{~g} / \mathrm{L}$ ammonium sulphate, $3 \mathrm{~g} / \mathrm{L}$ disodium hydrogen phosphate, $0.05 \mathrm{~g} / \mathrm{L}$ magnesium heptahydrate. Culture media $\mathrm{pH}$ was adjusted to 6.8 using $1 \mathrm{M}$ sodium hydroxide. Trials were carried out at for 5 days, with an agitation at $150 \mathrm{rpm}$ in $30^{\circ} \mathrm{C}$ in $200-\mathrm{mL}$ shake flasks. At the end of the experiment, microbial cellulose concentration was determined and the best substrate concentration was used for further investigation.

\subsection{Analytical Methods}

Fermentation broth from shake flasks was harvested and homogenized. Collected broth samples were centrifuged for 20 minutes at $4000 \mathrm{rpm}$, washed with distilled water and centrifuged again to remove culture media. The washed pellets were treated with $1 \mathrm{M}$ sodium hydroxide at $90^{\circ} \mathrm{C}$ for 30 minutes to suspend cells. Subsequently, the microbial cellulose was centrifuged again for 20 minutes at $4000 \mathrm{rpm}$, washed with distilled water and followed by drying process at $80^{\circ} \mathrm{C}$ for 24 hours. The dried pellets were then weighed.

\section{RESULTS AND DISCUSSION}

\subsection{Influence of Saccharide Types on G. xylinus Growth}

Both agar slants and shake flasks media were prepared aseptically, utilizing different carbon sources. All flask was inoculated with cultures of G. xylinus. The aerobic fermentation was carried out at $30^{\circ} \mathrm{C}$. Shake flasks which were equipped with cotton plug were agitated at 150 rpm in a shaker incubator.

After five days, it was observed that small colonies appeared on glucose agar slants. However, there was no growth appeared on both sucrose agar slants and shake flasks media. Weak growth was observed on lactose agar slants and in lactose shakes flasks media (Table 1). 
Table 1. Effect of saccharides on growth of G. xylinus DSM 46604 after 5 days on agar slants and in agitated shake flasks

\begin{tabular}{ccc}
\hline Carbon Sources/Saccharides & Agar Slants & Shake Flasks \\
\hline Glucose & + & + \\
Sucrose & - & - \\
Lactose & -+ & -+ \\
\hline +: positive growth -+ negligible -: no growth
\end{tabular}

There was lavish growth in fermentation broth and on agar slants containing glucose after five days but no visible growth appeared in fermentation broth and on agar slants, which were supplemented with sucrose and lactose. Consequently, this result was an unpredicted because much studies had employed numerous strains of G. xylinusbacteria on sucrose [15], lactose [16] and mannitol [17].

Due to the major catabolism and anabolism pathways; citric acid cycle and pentose phosphate cycle for carbohydrates oxidation, there was a different respond among carbon sources in producing colonies and cellulose [18]. In [19] reported that microbial cellulose production on sucrose was delayed by 12 hours compared with other saccharides. This scenario occurred as sucrose could not be conveyed through the cell membrane and break down to smaller unit of monosaccharides, which were glucose and fructose in the periplasm [20]. On the other hand, the microbial cellulose production when G. xylinus DSM 46604 is grown on both lactose agar slants and lactose culture media also showed weak respond. In addition, data in Table 1 were identical to those evaluated by [21] who stated that the IFO 15237 and ATCC 35959 strains of G. xylinus did not grow on lactose and sucrose.

The consequence of this trial is that glucose was the most ideal saccharide for microbial cellulose production. Many studies report that microbial cellulose productivity could be improved by identifying the suitable carbon source. For example, [22] obtained encouraging microbial cellulose concentration when utilized glucose as the carbon source. However, high concentrations of glucose can interfere cell mass and microbial cellulose production by G. xylinus due to buildup of gluconic acids [23]. 
Fermenting G. xylinus DSM 46604 in shake flasks with varied glucose concentrations revealed an increment in microbial cellulose concentration when glucose was increased from 40 to $50 \mathrm{~g} / \mathrm{L}$. However, a reduction of cellulose concentration when higher glucose concentrations (60, 80 and $100 \mathrm{~g} / \mathrm{L})$ were applied (Fig. 1).

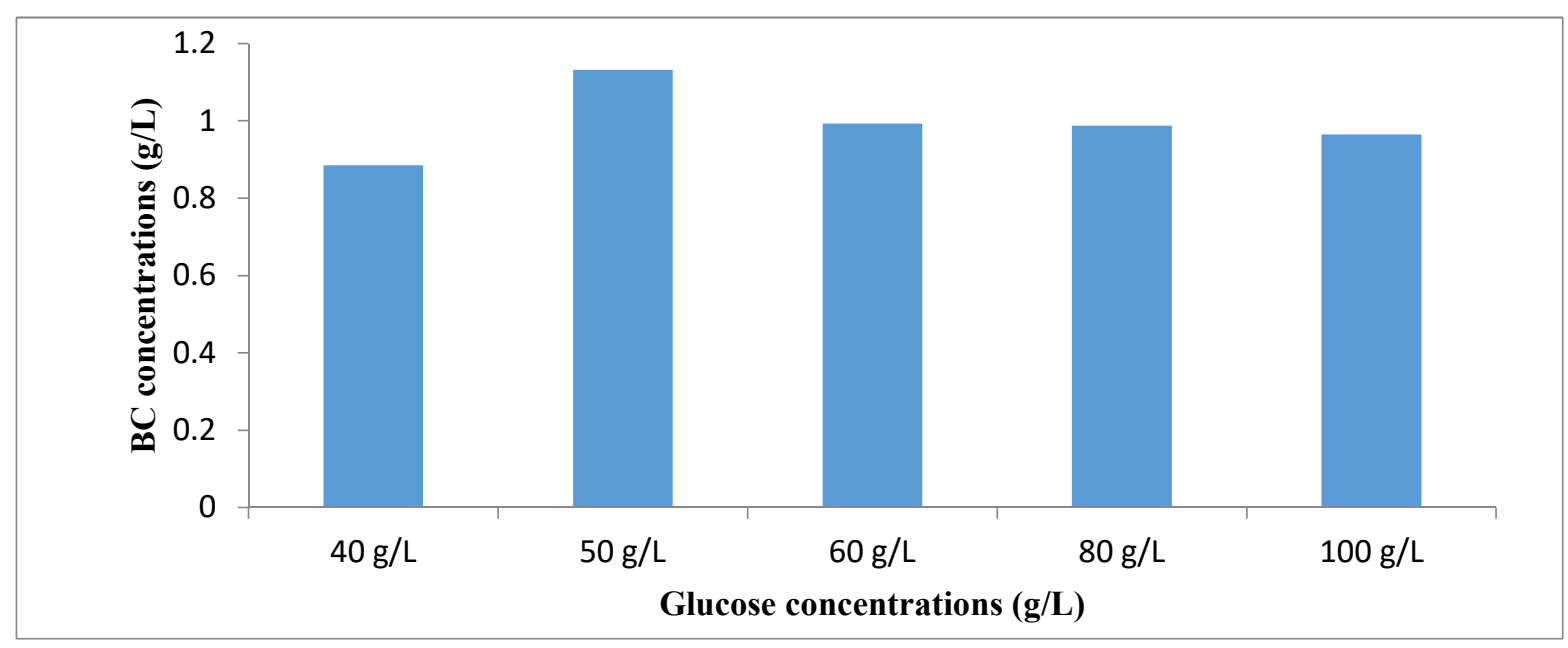

Fig.1. Influence of glucose concentration on microbial cellulose concentration by G. xylinus DSM 46604

\subsection{Influence of Initial Glucose Concentration on Microbial Cellulose Concentration}

In [8] reported that microbial cellulose production depleted if initial glucose concentration was beyond $40 \mathrm{~g} / \mathrm{L}$. However, other scientists have utilized higher saccharide concentrations. In [24] utilized $50 \mathrm{~g} / \mathrm{L}$ glucose, sucrose or mannitol. In [25] also used the same concentration of glucose for fermenting microbial cellulose.

Fifty $\mathrm{g} / \mathrm{L}$ of initial glucose concentration was found to be an ideal concentration, which is identical with the initial glucose concentrations most researchers used, even though [8] reported that using glucose concentrations greater than $40 \mathrm{~g} / \mathrm{L}$ reduced microbial cellulose concentration.

To make a comparison, $50 \mathrm{~g} / \mathrm{L}$ glucose in this study gave $1.13 \mathrm{~g} / \mathrm{L}$ (Fig. 1) of microbial cellulose concentration which is much lower than $3.5 \mathrm{~g} / \mathrm{L}$, obtained by [24] in shake flasks cultivation. In [9] cultured G. xylinus ATCC 53582 in lidded glass tubes, obtained approximately $0.62 \mathrm{~g}$ microbial cellulose from $20 \mathrm{~g} / \mathrm{L}$ D-glucose media at $\mathrm{pH} 5$. 


\section{CONCLUSION}

The bacteria G. xylinus DSM 46604 secreted microbial cellulose when grown on glucose media with conventional nitrogen sources such as ammonium sulphate and yeast extract. Supplementing glucose concentrations greater than $50 \mathrm{~g} / \mathrm{L}$ decreased microbial cellulose concentration.

\section{ACKNOWLEDGEMENTS}

The authors would like to acknowledge the scholarships from Ministry of Higher Education Malaysia and Universiti Malaysia Terengganu (UMT) for carrying out this research at The University of Waikato.

\section{REFERENCES}

[1] Khalil H A, Bhat A H, Yusra A I. Green composites from sustainable cellulose nanofibrils: A review. Carbohydrate Polymers, 2012, 87(2):963-979

[2] Brown R M. Cellulose structure and biosynthesis: What is in store for the 21th century? Journal of Polymer Science Part A: Polymer Chemistry, 2004, 42(3):487-495

[3] Hornung M, Ludwig M, Gerrard A M, Schmauder H P. Optimizing the production of bacterial cellulose in surface culture: Evaluation of product movement influences on the bioreaction (Part 2). Engineering in Life Sciences, 2006, 6(6):546-551

[4] Hong F, Qiu K. An alternative carbon sources from konjac powder for enhancing production of bacterial cellulose in static cultures by a model strain Acetobacteraceti subsp. xylinus ATCC23770. Carbohydrate Polymers, 2008, 72(3):545-549

[5] Karahan A G, Akoğlu A, Çakır İ, Kart A, Çakmakçı M L, Uygun A, Göktepe F. Some properties of bacterial cellulose produced by new native strain Gluconacetobacter sp. A06O2 obtained from Turkish vinegar. Journal of Applied Polymer Science, 2011, 121(3):1823-1831

[6] Yusra A I, Khalil H A, Hossain M S, Davoudpour Y, Astimar A A, Zaidon A, Dungani R, Omar A M. Characterization of plant nanofiber-reinforced epoxy composites. BioResources, 2015, 10(4):8268-8280

[7] Abdul K H P, Bhat I, Ireana Y A F, Sanusi Z A, Hezri A A. Broad perspective of palm oil for non-food applications for sustainable tomorrow. New York: Nova Science, 2011 
[8] Masaoka S, Ohe T, Sakota N. Production of cellulose from glucose by Acetobacterxylinum. Journal of Fermentation and Bioengineering, 1993, 75(1):18-22

[9] Ishihara M, Matsunaga M, Hayashi N, Tišler V. Utilization of D-xylose as carbon source for production of bacterial cellulose. Enzyme and Microbial Technology, 2002, 31(7):986-991 [10] Shoda M, Sugano Y. Recent advances in bacterial cellulose production. Biotechnology and Bioprocess Engineering, 2005, 10(1):1-8

[11] Brown A J. XLIII. On an acetic ferment which forms cellulose. Journal of the Chemical Society, Transactions, 1886, 49:432-439

[12] Nakagaito A N, Iwamoto S, Yano H. Bacterial cellulose: The ultimate nanoscalar cellulose morphology for the production of high strength composites. Applied Physics A: Materials Science and Processing, 2005, 80(1): 93-97

[13] Brown E E, Laborie M P. Bioengineering bacterial cellulose/poly(ethylene oxide) nanocomposites. Biomacromolecules, 2007, 8(10):3074-3081

[14] Kalia S, Dufresne A, Cherian B M, Kaith B S, Avérous L, Njuguna J, Nassiopoulos E. Cellulose-based bio and nanocomposites: A review. International Journal of Polymer Science, 2011, 2011:1-35

[15] Pourramezan G Z, Royaei A M, Qezelbash Q R. Optimization of culture conditions for bacterial cellulose production by Acetobacter sp. 4B-2. Biotechnology, 2009, 8(1):150-154

[16] Mohite B V, Salunke B K, Patil S V. Enhanced production of bacterial cellulose by using Gluconacetobacterhansenii NCIM 2529 strain under shaking conditions. Applied Biochemistry and Biotechnology, 2013, 169(5):1497-1511

[17] Nguyen V T, Flanagan B, Gidley M J, Dykes G A. Characterization of cellulose production by a Gluconacetobacterxylinus strain from kombucha. Current Microbiology, 2008, 57(5):449-453

[18] Ross P, Mayer R, Benziman M. Cellulose biosynthesis and function bacteria. Microbiological Reviews, 1991, 55(1):35-58

[19] Mikkelsen D, Flanagan B M, Dykes G A, Gidley M J. Influence of different carbon sources on bacterial cellulose production by Gluconacetobacterxylinus strain ATCC 53524 . Journal of Applied Microbiology, 2009, 107(2):576-583 
[20] Velasco-Bedrán H, López-Isunza F. The unified metabolism of Gluconacetobacterentanii in continuous and batch processes. Process Biochemistry, 3007, 42(8):1180-1190

[21] Tsuchida T, Yoshinaga F. Production of bacterial cellulose by agitation culture systems. Pure and Applied Chemistry, 1997, 69(11): 2453-2458

[22] Heo M S, Son H J. Development of an optimized, simple chemically defined medium for bacterial cellulose production by Acetobacter sp. A9 in shaking cultures. Biotechnology and Applied Biochemistry, 2000, 36(1):41-45

[23] Vandamme E J, De Baets S, Vanbaelen A, Joris K, De Wulf P. Improved production of bacterial cellulose and its application potential. Polymer Degradation and Stability, 1998, 59(1-3):93-99

[24] Ramana K V, Tomar A, Singh L. Effect of various carbon and nitrogen sources on cellulose synthesis by Acetobacterxylinum. World Journal of Microbiology and Biotechnology, 2000, 16(3):245-248

[25] Chávez-Pacheco J L, Martínez-Yee S, Contreras M L, Gómez-Manzo S, Membrillo-Hernández J, Escamilla J E. Partial bioenergetic characterization of Gluconacetobacterxylinum cells released from cellulose pellicles by a novel methodology. Journal of Applied Microbiology, 2005, 99(5):1130-1140

\section{How to cite this article:}

Adnan A, Nair GR, Lay MC, Swan JE, Umar R, Yusra AFI. Influences of saccharides types and initial glucose concentration on microbial cellulose production by g. xylinus. J. Fundam. Appl. Sci., 2017, 9(2), 174-181. 